08

\title{
Эффект насыщающегося поглотителя в длинноволновых вертикально-излучающих лазерах, реализованных по технологии спекания
}

(C) С.А. Блохин ${ }^{1}$, М.А. Бобров ${ }^{1}$, А.А. Блохин ${ }^{2}$, А.П. Васильев ${ }^{2}$, А.Г. Кузьменков ${ }^{2}$, Н.А. Малеев ${ }^{1,3}$, С.С. Рочас ${ }^{4}$, А.Г. Гладышев ${ }^{4,5}$, А.В. Бабичев ${ }^{4,5}$, И.И. Новиков ${ }^{4}$, Л.Я. Карачинский ${ }^{4,5}$, Д.В. Денисов ${ }^{3}$, К.О. Воропаев ${ }^{6,7}$, А.С. Ионов ${ }^{7}$, А.Ю. Егоров ${ }^{4}$, В.М. Устинов ${ }^{2,3}$

${ }^{1}$ Физико-технический институт им. А.Ф. Иофффе РАН, Санкт-Петербург, Россия

2 Научно-технологический центр микроэлектроники и субмикронных гетероструктур РАН, Санкт-Петербург, Россия

${ }^{3}$ Санкт-Петербургский государственный электротехнический университет „ЛЭТИ“, Санкт-Петербург, Россия

${ }^{4}$ Университет ИТМО, Санкт-Петербург, Россия

${ }^{5}$ ООО „Коннектор Оптикс“, Санкт-Петербург, Россия

${ }^{6}$ Новгородский государственный университет им. Ярослава Мудрого, Великий Новгород, Россия

${ }^{7}$ АО „ОКБ-Планета“, Великий Новгород, Россия

E-mail: blokh@mail.ioffe.ru

Поступило в Редакцию 20 августа 2020г.

В окончательной редакции 17 сентября 2020 r.

Принято к публикации 17 сентября 2020г.

Исследованы вертикально-излучающие лазеры спектрального диапазона $1.55 \mu \mathrm{m}$ на основе гетероструктур с заращенным туннельным переходом (ЗТП) с перепадом высоты $15 \mathrm{~nm}$. Приборы получены с использованием технологии спекания из гетероструктур, выращенных методом молекулярно-пучковой эпитаксии, и демонстрируют одномодовый режим генерации при диаметре ЗТП вплоть до $8 \mu \mathrm{m}$. При уменьшении размера ЗТП наблюдаются резкий рост порогового тока, скачкообразное возрастание выходной оптической мощности и резонансной частоты на пороге генерации. Стабильная одномодовая генерация обусловлена сглаживанием границы заращенного поверхностного рельефа, приводящим к плавному изменению профиля эффективного показателя преломления в латеральном направлении при сохранении эффективного электронного ограничения, что позволяет существенно уменьшить фактор поперечного оптического ограничения для мод высокого порядка даже при больших размерах ЗТП. Однако при малых размерах ЗТП это приводит к формированию насыщающегося поглотителя в непрокачиваемых частях активной области.

Ключевые слова: вертикально-излучающий лазер, спекание пластин, насыщающийся поглотитель.

DOI: 10.21883/PJTF.2020.24.50430.18522

Длинноволновые вертикально-излучающие лазеры (ВИЛ, ангЛ. vertical-cavity surface-emitting laser) перспективны для применения в цифровых и аналоговых оптических каналах связи, оптических межсоединениях, кремниевых фотонных схемах и для создания различного рода газовых сенсоров [1]. Для большинства упомянутых приложений требуется выходная оптическая мощность на уровне нескольких $\mathrm{mW}$ в одномодовом режиме генерации. С учетом ряда фундаментальных ограничений, присущих системам материалов InAlGaAs/GaAs и InAlGaAsP/InP, наиболее перспективным решением является применение гибридной конструкции длинноволновых ВИЛ с распределенными брэгговскими отражателями (РБО, англ. distributed Bragg reflector), обладающими высокой отражательной способностью и теплопроводностью [2,3], и инжекцией носителей заряда в активную область через внутрирезонаторные контакты и заращенный туннельный переход $n^{++} / p^{++}-\operatorname{In}(\mathrm{Al}) \mathrm{GaAs}$ (ЗТП, англ. buried tunnel junction). В рамках концепции ЗТП формирование поверхностного рельефа в $n$-слое туннельного перехода с последующим заращиванием слоем $n$-InP обеспечивает не только эффективное токовое ограничение за счет формирования обратносмещенного $p^{+}-n$-диода, но и эффективное оптическое ограничение за счет волноводного эффекта в поперечном направлении [4]. Однако технология молекулярно-пучковой эпитаксии (МПЭ, англ. molecular beam epitaxy) в отличие от технологии газофазной эпитаксии из металлоорганических соединений (англ. metalorganic chemical vapour deposition) не позволяет обеспечить планаризацию поверхности при заращивании поверхностного рельефа [5], что ведет к увеличению скачка эффективного показателя преломления. В результате одномодовая генерация возможна лишь при ультрамалых диаметрах ЗТП, для которых высокое электрическое и тепловое сопротивления ограничивают выходную оптическую мощность. В рамках гибридной конструкции ВИЛ с высококонтрастными диэлектрическими РБО уменьшение актуальной глубины травления туннельного перехода (т.е. толщины $n$-слоя) позволяет частично решить данную проблему [6], а применение дополнительного рельефа в контактном слое $n$-InGaAs позволяет сохранить одномодовый режим генерации вплоть до диаметров ЗТП $7 \mu \mathrm{m}[7]$. 

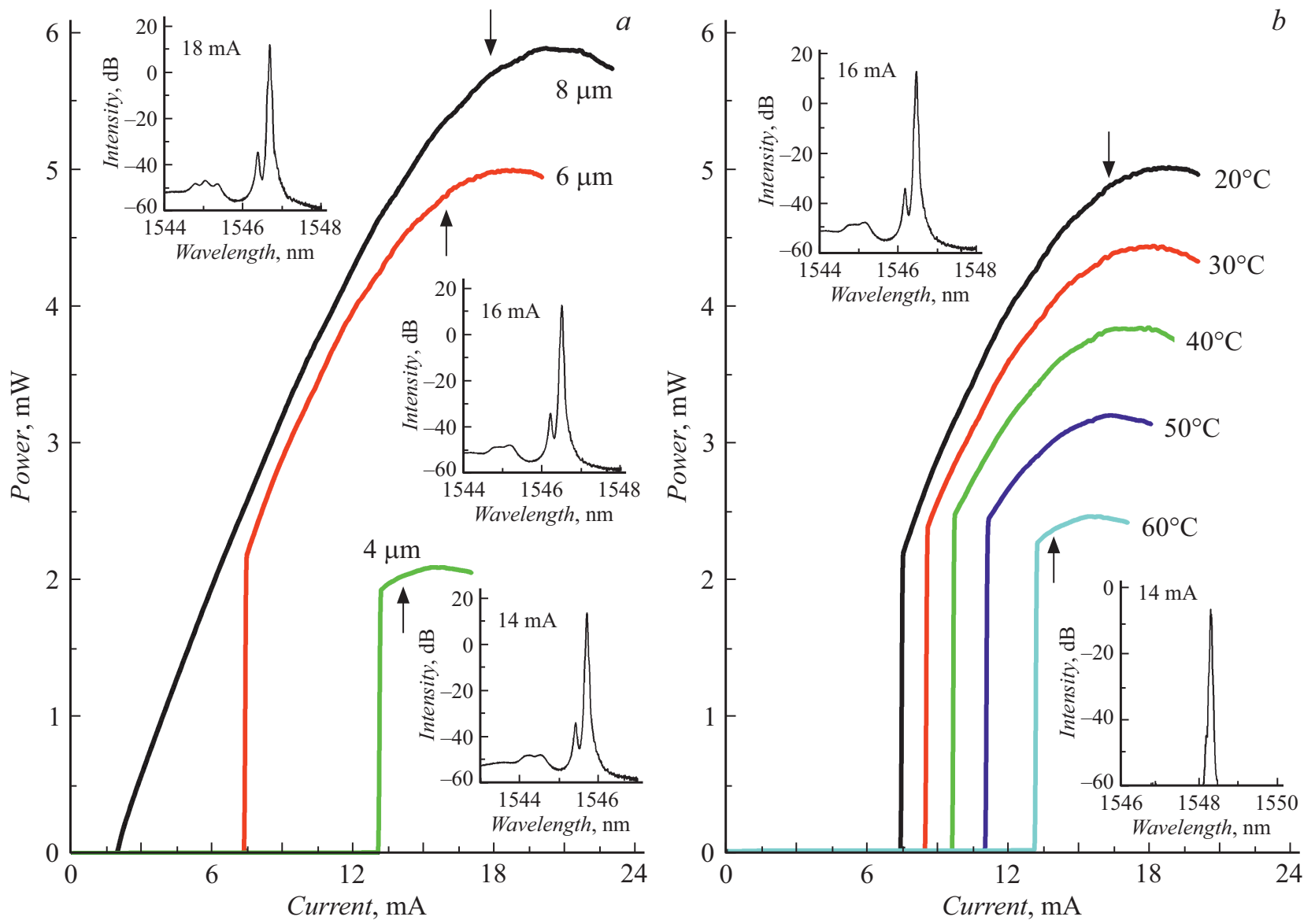

Рис. 1. $a$ - ватт-амперные характеристики и характерные спектры излучения (на вставках) для СП-ВИЛ спектрального диапазона $1.55 \mu \mathrm{m}$ с различным диаметром ЗТП, измеренные при $20^{\circ} \mathrm{C} ; b-$ ватт-амперные характеристики и характерные спектры излучения (на вставках) для СП-ВИЛ спектрального диапазона $1.55 \mu \mathrm{m} \mathrm{c} \mathrm{диаметром} \mathrm{ЗТП} 6 \mu \mathrm{m}$, измеренные при различной температуре.

Недавно нами была предложена оригинальная конструкция туннельного перехода $n^{++}-\mathrm{InGaAs} / p^{++}$ $\mathrm{InGaAs} / p^{++}$-InAlGaAs, позволяющая эффективно использовать технологию МПЭ для заращивания поверхностного рельефа [8], а также выполнять двукратное спекание гетероструктур $\mathrm{AlGaAs} / \mathrm{GaAs}$ и InAlGaAsP/InP для формирования гибридной конструкции ВИЛ спектрального диапазона $1.55 \mu \mathrm{m}$ [9]. В настоящей работе представлены результаты апробации такой конструкции, приведен анализ причин сохранения одномодового режима генерации при диаметре ЗТП до $8 \mu \mathrm{m}$ и исследован механизм возникновения резкого возрастания выходной мощности на пороге генерации при меньших размеpax ЗТП.

При последовательном спекании гетероструктуры оптического резонатора InAlGaAsP/InP с гетероструктурами верхнего и нижнего РБО GaAs/AlGaAs формируется гибридная гетероструктура (далее СП-ВИЛ), состоящая из нелегированной подложки GaAs, нижнего РБО на основе 35 пар четвертьволновых слоев $\mathrm{AlGaAs} / \mathrm{GaAs}$, нижнего внутрирезонаторного контактного слоя $n$-InP толщиной $\lambda$ с сильнолегированным контактным слоем $n$-InGaAsP, активной области на основе напряженных квантовых ям InGaAs, эмиттера $p$-InAlAs, ЗТП $n^{++}$ $\mathrm{InGaAs} / p^{++}-\mathrm{InGaAs} / p^{++}$-InAlGaAs с глубиной травления $15 \mathrm{~nm}$, верхнего внутрирезонаторного контактного слоя $n$-InP толщиной $\lambda$ с сильнолегированным контактным слоем $n$-InGaAsP, верхнего РБО на основе 20 пар четвертьволновых слоев $\mathrm{AlGaAs} / \mathrm{GaAs}$. Эпитаксиальный рост гетероструктур верхнего и нижнего РБО $\mathrm{AlGaAs} / \mathrm{GaAs}$ на подложках GaAs и гетероструктуры оптического полурезонатора InAlGaAsP на подложке InP, а также процесс заращивания поверхностного рельефа слоем $n$-InP выполнялись в рамках технологии МПЭ. Более детальное описание конструкции и нюансов изготовления исследуемых лазеров приведено в работах $[8,9]$.

На рис. 1, $а$ приведены типичные зависимости выходной оптической мощности от тока накачки СП-ВИЛ с разным диаметром ЗТП, измеренные в непрерывном режиме при температуре $20^{\circ} \mathrm{C}$. Все приборы демонстрируют стабильную одномодовую генерацию. При этом лазеры с большим диаметром ЗТП $(8 \mu \mathrm{m})$ демонстрируют классический ход ватт-амперной характеристики (ВтАХ) с пороговым током $\sim 2 \mathrm{~mA}$. Однако при меньшем диаметре ЗТП наблюдается скачкообразное возрастание выходной оптической мощности с током накачки 
на пороге генерации и увеличение наблюдаемой величины порогового тока (далее нелинейность ВтАХ). При этом чем меньше размер ЗТП, тем выше наблюдаемый пороговый ток. Более того, на ВтАХ также наблюдается небольшая область гистерезиса (данные здесь не приводятся). Следует отметить, что уменьшение потерь на вывод излучения в структурах с увеличенным коэффициентом отражения РБО ослабляет данный эффект, сдвигая момент появления нелинейности ВТАХ в сторону меньших размеров ЗТП. С повышением рабочей температуры проявление эффектов нелинейности ВТАХ усиливается (рис. 1,b). Падение дифференциальной эффективности для малых размеров ЗТП, наблюдаемое выше порога генерации, по-видимому, обусловлено дифракционными потерями на границе ЗТП, а также, как показано далее, падением фактора оптического ограничения.

Возможное объяснение наблюдаемых эффектов резким изменением потерь на вывод излучения с ростом тока/температуры для исследуемых лазеров представляется маловероятным ввиду слабой температурной зависимости показателей преломления и пренебрежимо малого термического расширения слоев $\mathrm{AlGaAs} / \mathrm{GaAs}$ РБО. Поскольку внутренние оптические потери для различных мод лазера могут существенно различаться, подобное поведение может быть обусловлено резким изменением модового состава излучения ВИЛ. В самом деле, подобного рода нелинейность ВТАХ наблюдалась в широкоапертурных ВИЛ спектрального диапазона $850 \mathrm{~nm}$ с двойной оксидной токовой апертурой при большой спектральной расстройке [10] и была связана с возникновением лазерной генерации через моды высшего порядка, локализованные на периферии токовой апертуры со специфическим профилем [11]. Однако все исследуемые приборы продемонстрировали одномодовый режим генерации с фактором подавления боковых мод более $30 \mathrm{~dB}$ во всем диапазоне токов накачки и рабочих температур (см. вставки к рис. 1); следовательно, наблюдаемая нелинейность ВтАХ не может быть связана с конкуренцией мод.

Обнаруженная нелинейность ВтАХ, сопровождаемая гистерезисом, ранее наблюдалась в ВИЛ с монолитноинтегрированным насыщающимся поглотителем на основе квантовых ям [12,13]. В рассматриваемых приборах наиболее вероятной причиной наблюдаемого поведения в исследуемых СП-ВИЛ является формирование насыщающегося поглотителя аналогично случаю ВИЛ спектрального диапазона $980 \mathrm{~nm}$ с оксидной токовой апертурой, где клиновидная форма токовой апертуры приводила к распространению электромагнитного поля моды в латеральном направлении и его поглощению в слабопрокачанных током частях активной области по периферии апертуры [14]. При достижении определенной плотности фотонов в резонаторе наблюдались насыщение поглощения и относительно резкий рост выходной мощности ВИЛ. Рассмотрим возможный механизм образования насыщающегося поглотителя в исследуемых CП-ВИЛ. Благодаря малой толщине эмиттера $p$-InAlAs латеральным растеканием тока можно пренебречь и принимать площадь прокачиваемой части активной области равной площади ЗТП. Анализ гетероструктур СПВИЛ методом просвечивающей электронной микроскопии [9] и изготовленных лазеров методом растровой электронной микроскопии с применением локального травления фокусированным пучком ионов не выявил образования воздушных полостей на границе ЗТП и/или интерфейсах спекания. Поскольку при МПЭ-заращивании поверхностного рельефа перепад высот сохраняется, контраст эффективного показателя преломления $\Delta n_{e f f}$ между частями СП-ВИЛ в центральной области ЗТП и в области периферийного блокирующего обратносмещенного $p^{+}-n$-диода можно оценить на уровне 0.01 , используя метод эффективного показателя преломления [15]. В то же время анализ поверхности гетероструктуры оптического резонатора с помощью атомно-силовой микроскопии выявил увеличение латеральных размеров поверхностного рельефа в 1.5-2 раза и латеральное сглаживание границы при сохранении перепада высот после заращивания туннельного перехода. В результате образуется эффективный волновод с градиентным профилем показателя преломления, который для упрощения расчетов был аппроксимирован пятью ступенями. На рис. 2, а приведены расчетные значения перекрытия между латеральным профилем интенсивности оптической моды и прокачиваемой частью активной области (так называемый фактор поперечного оптического ограничения $\Gamma_{t r}$ ) в зависимости от диаметра ЗТП для первых трех мод, существующих в таком пятиступенчатом эффективном волноводе. По аналогии c [16] наличие протяженного градиента эффективного показателя преломления позволяет растянуть распределение электромагнитного поля в поперечном направлении и в существенной степени уменьшить величину $\Gamma_{t r}$ для мод высокого порядка (рис. 2, b). Это позволяет увеличить разницу в величине модального усиления и обеспечить реализацию одномодового режима генерации СП-ВИЛ при бо́льших размерах ЗТП. В то же время с уменьшением диаметра ЗТП уже для фундаментальной моды наблюдается падение величины $\Gamma_{t r}$, ведущее к пропорциональному увеличению доли перекрытия интенсивности электромагнитного поля фундаментальной моды с непрокачиваемой периферийной частью активной области (рис. 2,b). При этом моделирование в одномерном приближении показывает, что достигаемый уровень модального усиления для фундаментальной моды остается по-прежнему достаточно высоким для преодоления суммарных оптических потерь при относительно малых токах накачки. Однако в реальных приборных структурах фотоны, рожденные в прокачиваемой центральной части активной области, поглощаются в ее непрокачиваемой периферийной части, и характерные признаки появления лазерной генерации не наблюдаются. С ростом плотности фотонов в резонаторе непрокачиваемая часть активной области просветляется, т. е. поглотитель насыщается, и происходит резкое увеличение 

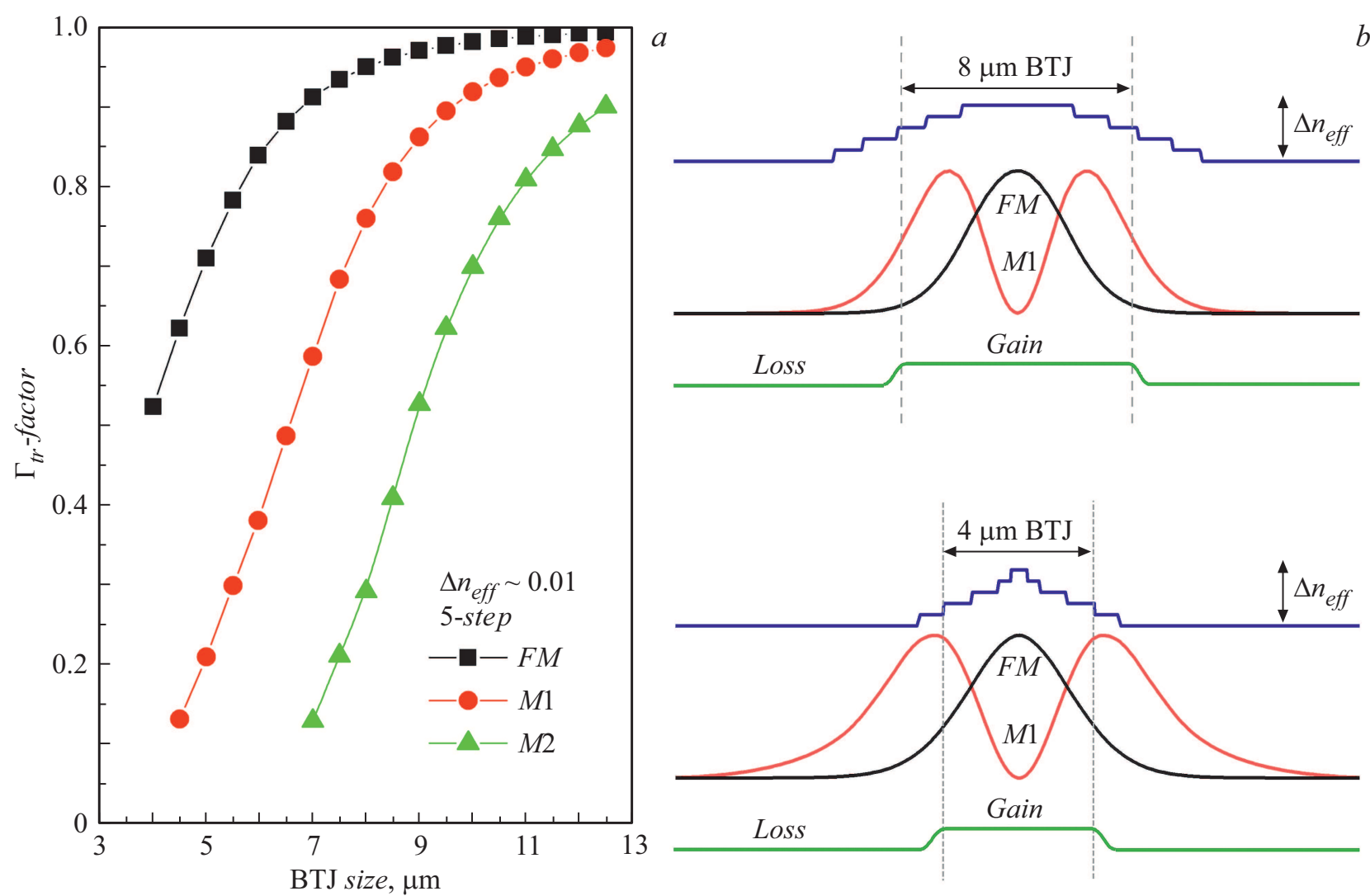

Рис. 2. Результаты моделирования СП-ВИЛ в рамках модели эффективного волновода. $a$ - зависимость фактора поперечного оптического ограничения $\Gamma_{t r}$ от диаметра ЗТП для мод низшего порядка; $b-$ схематические распределения электромагнитного поля фундаментальной моды и моды первого порядка вдоль профиля показателя преломления при диаметре 3 TП 4 и $8 \mu \mathrm{m}$. FM фундаментальная мода, $M 1$ - мода первого порядка, $M 2$ - мода второго порядка, ВТЈ - заращенный туннельный переход.

выходной оптической мощности лазера на наблюдаемом пороге генерации. Для исследуемых СП-ВИЛ по мере увеличения рабочей температуры уменьшается значение спектральной расстройки максимума оптического усиления и резонансной длины волны, что ведет к росту уровня оптического поглощения света на резонансной длине волны в непрокачиваемых частях активной области и усилению эффекта насыщающегося поглотителя, приводящего к усилению эффектов нелинейности ВТАХ.

В пользу предложенного объяснения механизма нелинейности ВТАХ свидетельствуют как сохранение высокой дифференциальной эффективности приборов при радикальном росте наблюдаемого порога генерации, так и результаты малосигнального частотного анализа отклика лазеров на гармоническую модуляцию током. На рис. 3 приведены зависимости частоты собственных релаксационных колебаний (так называемой резонансной частоты) от тока накачки. Лазеры с классическим поведением ВТАХ (случай СП-ВИЛ с диаметром ЗТП $8 \mu \mathrm{m})$ демонстрируют плавное увеличение резонансной частоты с ростом тока накачки, что соответствует классическому поведению. В лазерах с нелинейной ВТАХ наблюдается скачкообразное увеличение резонансной частоты выше порога генерации, как в случае СП-ВИЛ с диаметром 3ТП $6 \mu \mathrm{m}$. Поскольку квадрат резонансной частоты прямо пропорционален плотности фотонов в резонаторе, наблюдаемое скачкообразное увеличение резонансной частоты свидетельствует о высокой плотности фотонов в лазерном резонаторе в момент начала генерации, что характерно для лазеров с насыщающимся поглотителем [13].

Таким образом, исследованные ВИЛ спектрального диапазона $1.55 \mu \mathrm{m}$, реализованные по технологии спекания методом МПЭ, демонстрируют стабильный одномодовый режим генерации вплоть до диаметра ЗТП $8 \mu \mathrm{m}$. Данный эффект обусловлен малой глубиной поверхностного рельефа, сформированного в слое туннельного перехода, и латеральным сглаживанием границы поверхностного рельефа при сохранении перепада высот после его заращивания методом МПЭ. Образующийся в этом случае эффективный волновод с градиентным профилем показателя преломления ведет к существенному снижению величины перекрытия поля мод высокого порядка с прокачиваемой частью активной области даже при больших размерах ЗТП. В то же время при уменьшении диаметра ЗТП наблюдается увеличение доли поля фундаментальной моды в непрокачиваемой периферийной части активной области, что ведет к 

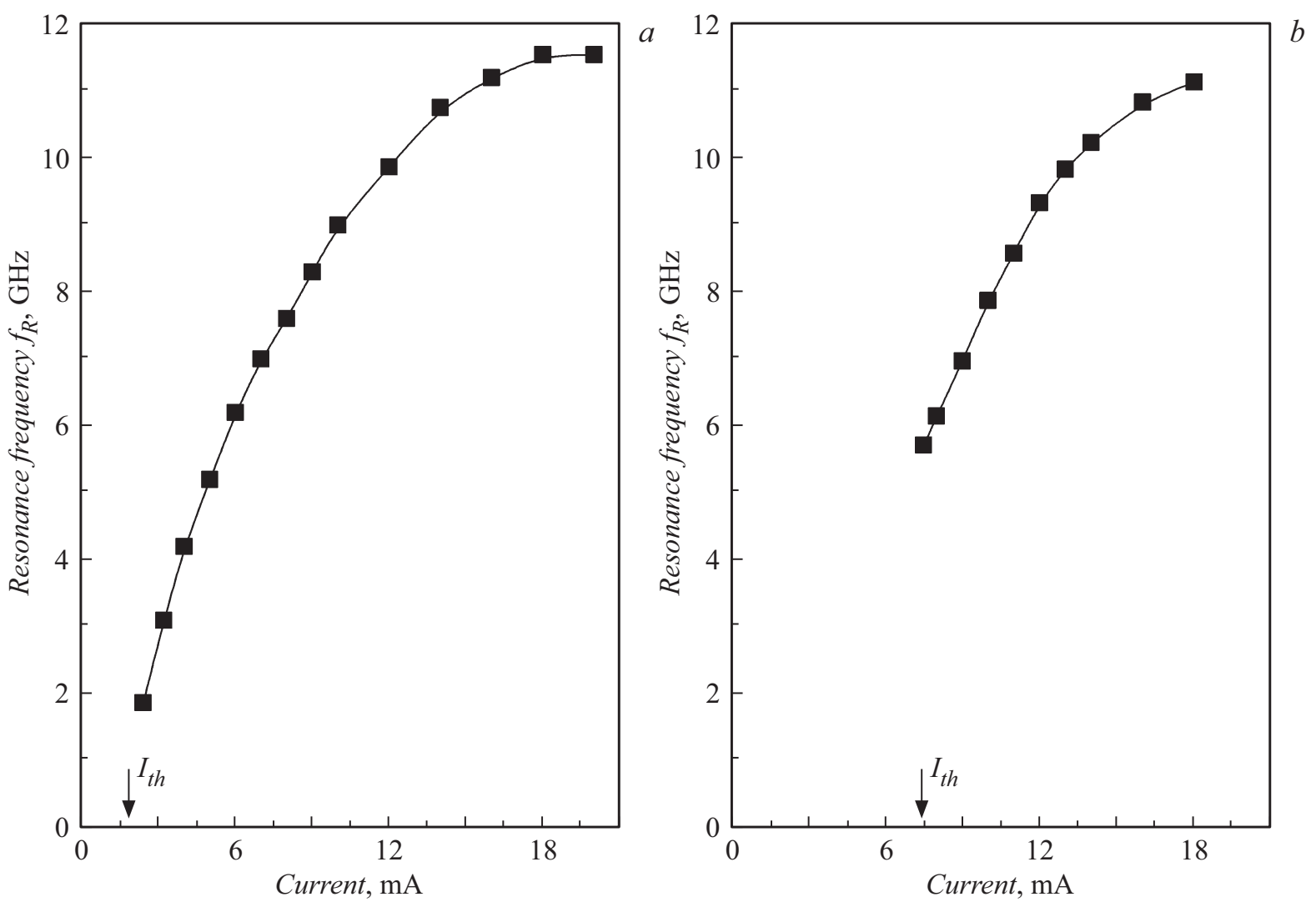

Рис. 3. Зависимости резонансной частоты от тока накачки для СП-ВИЛ спектрального диапазона $1.55 \mu \mathrm{m}$ с диаметром 3 ТП 8 (a) и $6 \mu \mathrm{m}(b)$, измеренные при $20^{\circ} \mathrm{C}$.

формированию насыщающегося поглотителя. По мере роста плотности фотонов в резонаторе с током накачки происходит просветление насыщающегося поглотителя и наблюдаются нелинейность ВтАХ (скачкообразное возрастание выходной мощности), сопровождаемая увеличением порогового тока, и скачкообразное увеличение резонансной частоты лазера при небольшом превышении порога генерации.

\section{Конфликт интересов}

Авторы заявляют, что у них нет конфликта интересов.

\section{Список литературы}

[1] Michalzik $R$. VCSELs: fundamentals, technology and applications of vertical-cavity surface-emitting lasers. Berlin: Springer-Verlag, 2013. $560 \mathrm{p}$. DOI: $10.1007 / 978-3-642-24986-0$

[2] Mereuta A., Caliman A., Syrbu A., Iakovlev V., Ellafi D., Rudra A., Wolf P., Bimberg D., Kapon E. // Proc. SPIE. 2016. V. 10017. P. 1001702. DOI: $10.1117 / 12.2246208$

[3] Spiga S., Schoke D., Andrejew A., Boehm G., Amann M.C. // IEEE J. Lightwave Technol. 2017. V. 35. N 15. P. 3130-3141. DOI: $10.1109 /$ JLT.2017.2660444
[4] Ortsiefer M., Shau R., Böhm G., Köhler F., Amann M.-C. // Appl. Phys. Lett. 2000. V. 76. N 16. P. 2179-2181. DOI: $10.1063 / 1.126290$

[5] Müller M., Debernardi P., Grasse C., Gründ T.L., Amann M.-C. // IEEE Photon. Technol. Lett. 2013. V. 25. N 2. P. 140-143. DOI: 10.1109/LPT.2012.2229975

[6] Spiga S., Soenen W., Andrejew A., Schoke D.M., Yin X., Bauwelinck J., Böhm G., Amann M.-C. // IEEE J. Lightwave Technol. 2017. V. 35. N 4. P. 727-733. DOI: $10.1109 /$ JLT.2016.2597870

[7] Gründl T., Debernardi P., Müller M., Grasse C., Ebert P., Geiger K., Ortsiefer M., Böhm G., Meyer R., Amann M.-C. // IEEE J. Sel. Top. Quant. Electron. 2013. V. 19. N 4. P. 1700913 DOI: 10.1109/JSTQE.2013.2244572

[8] Блохин С.А., Бобров М.А., Малеев Н.А., Блохин А.А., Кузьменков А.Г., Васильев А.П., Рочас С.С., Гладышев А.Г., Бабичев А.В., Новиков И.И., Карачинский Л.Я., Денисов Д.В., Воропаев К.О., Ионов А.С., Егоров А.Ю., Устинов В.М. // Письма в ЖТФ. 2020. Т. 46. В. 17. С. 2125. DOI:10.21883/PJTF.2020.17.49888.18393

[9] Блохин С.А., Неведомский В.Н., Бобров М.А., Малеев Н.А., Блохин А.А., Кузьменков А.Г., Васильев А.П., Рочас С.С., Бабичев А.В., Гладышев А.Г., Новиков И.И., Карачинский Л.Я., Денисов Д.В., Воропаев К.О., Ионов А.С., Егоров А.Ю., Устинов В.М. // ФТП. 2020. Т. 54. В. 10. С. 1088-1096. DOI: 10.21883/FTP.2020.10.49947.9463 
[10] Blokhin S.A., Bobrov M.A., Maleev N.A., Kuzmenkov A.G., Sakharov A.V., Blokhin A.A., Moser P., Lott J.A., Bimberg D., Ustinov V.M. // Appl. Phys. Lett. 2014. V. 105. N 6. P. 061104. DOI: $10.1063 / 1.4892885$

[11] Блохин С.А., Бобров М.А., Малеев Н.А., Кузьменков А.Г., Устинов В.М. // Оптика и спектроскопия. 2020. Т. 129. B. 2. C. 1151-1159. DOI: 10.21883/OS.2020.08.49713.148-19

[12] Lim S.F., Hudgings J.A., Li G.S., Yuen W., Lau K.Y., ChangHasnain C.J. // IEEE Electron. Lett. 1997. V. 33. N 20. P. 1708-1710. DOI: 10.1049/el:19971121

[13] Hudgings J.A., Stone R.J., Chang C.-H., Lim S.F., Lau K.Y., Chang-Hasnain C.J. // IEEE J. Sel. Top. Quant. Electron. 1999. V. 5. N 3. P. 512-519. DOI: $10.1109 / 2944.788413$

[14] Kuzmenkov A.G., Ustinov V.M., Sokolovskii G.S., Maleev N.A., Blokhin S.A., Deryagin A.G., Chumak S.V., Shulenkov A.S., Mikhrin S.S., Kovsh A.R., McRobbie A.D., Sibbett W., Cataluna M.A., Rafailov E.U. // Appl. Phys. Lett. 2007. V. 91. N 12. P. 121106 . DOI: $10.1063 / 1.2784937$

[15] Hadley G.R. // Opt. Lett. 1995. V. 20. N 13. P. 1483-1485. DOI: $10.1364 /$ OL.20.001483

[16] Blokhin S.A., Maleev N.A., Kuzmenkov A.G., Sakharov A.V., Kulagina M.M., Shernyakov Y.M., Novikov I.I., Maximov M.V., Ustinov V.M., Kovsh A.R., Mikhrin S.S., Ledentsov N.N., Lin G., Chi J.Y. // / IEEE J. Quant. Electron. 2006. V. 42. N 9. P. 851-858. DOI: 10.1109/JQE.2006.880125 